\title{
Using the Interpersonal Relationship Communication Approach to Assess Language Dominance in both Written and Oral Communication among Multilinguals
}

Olusiji Lasekan $^{+*}$

\section{Abstract}

Copious research works have attempted to assess language dominance among bilinguals. However, very little empirical research has been conducted to determine the concept among multilingual by using interpersonal relationships communication domains such as families, friendships, and acquaintances. This is crucial because the choice of language use between two interlocutors in any domain depends on the level of social relation that exists between them. Therefore, this current study aims to determine language dominance for oral and written communication at different domains of interpersonal relationships such as family, friends, and acquaintance. Each domain size was used as a proxy to measure language dominance among different groups of multilingual living in the Southern part of India. As part of this study, a structured sociolinguistics questionnaire that probes the use of the Facebook Friend Lists feature was adopted to determine each domain size and language use in each domain. The questionnaire was administered among forty-three multilingual postgraduate students. The result showed that the dominant language for oral and written communication in the entire geographical setting is the first language (L1) and English, respectively. This suggests that the interpersonal relationship communication approach is practical to determine language dominance in a community.

Keywords: Dominance; Multilingual; Interpersonal Relationships; India

\footnotetext{
† Pedagogía en Inglés, Departamento de Educación Media, Universidad Católica de Temuco, Chile, Email: olasekan@uct.cl

(C) 2020 Lasekan. This is an Open Access article distributed under the terms of the Creative Commons Attribution License (http://creativecommons.org/licenses/by/2.0), which permits unrestricted use, distribution, and reproduction in any medium, provided the original work is properly cited.
} 


\section{Introduction}

In recent years, there has been an increasing interest in language dominance among bilingual researchers. Continuous development of this discourse stemmed from its significant application in the field of education, commerce, and clinical research (Gertken et al., 2014). Brunner's (2010) study (as cited by Gertken et al., 2014) adopted the dominance concept to determine students' linguistics ability, which is consequently used as a tool to plan bilingual education. The construct has also been found to be relevant in the area of clinical research. For example, language therapy treatment for Alzheimer patient since both the dominant and recessive language is affected by the disease (Gollan et al., 2011). In Indian setting, Fishman (1986) investigated the dominance of language in different social institutions such as home, school, workplace, marketplace, amongst others. English, which is the official language, serves different purposes and functions in different domains. For instance, it is considered to be a language of administration in workplaces, language of science in schools, language of Pan-Indian press in media, and language of the law in courts (Görlach, 1991, p. 29). However, the limitation of some of these studies is that social institutions such as home and workplace are not suitable enough to determine the language dominance in these domains. This is because the choice of language for Face to Face communication is highly determined by the degree of interpersonal social relations that exist among interlocutors of the same multilingual community (Lasekan, 2018). Furthermore, due to inconsistency associated with its' measurement between two or more languages of a bi/multilingual, it is crucial in creating an objective assessment that can be replicated and compared, which in turn improves the interpretation of results (Yip \& Matthews, 2006). Thus, this study is mainly concerned with the usage of interpersonal relationship communication as a model to investigate dominance in both oral and written communication among families, friends, and acquaintances, which consequently predicts the degree of dominance at home, other social institution domains, and the whole community. Thus, this paper begins by reviewing the literature. It will then go on to methodology which is followed by discussion. Finally, the conclusion gives a summary and critique of the findings.

\section{Literature Review}

Although there is a consensus among scholars on the occurrence and existence of language dominance, there is still no agreement on the definition of language dominance. There is a plethora of definitions of dominance that is coined from various scholarly points of view. Some definitions are based on proficiency, frequent language usage, language exposure, cultural identification, and psycholinguistic. In order to summarize different ways, dominance has been defined in the body of literature. Petersen (1988, pp. 486-487) postulated four different perspectives of dominance. From the viewpoint of language behaviour, individual dominancy is equivalent to language proficiency. From the stands point of code-switching, the dominant language is the one in which an individual can communicate without the need to code-switch. Peterson also stated that individual dominance in a multilingual community could be determined by the language domain in which an individual spends most of his or her time. The last criterion is based on the lexical to grammatical morpheme use by a bilingual speaker. In sum, it is possible to establish a relationship between language use in a domain and language dominance. That is, different languages can be dominant in different domains. This is exemplified in the Indian context, the apparent dominant language at home is Mother tongue because it is frequently used compared to English in other social spheres. Thus, the variance in dominance is a function of an individual's time and exposure to those domains. In other words, the user's fluency in a language is expected to develop when the environment does not support or encourage code-switching. 
Based on Peterson's posit, it can be observed that the common notion associated with dominance is proficiency. However, the causal relationship between the two concepts has been heavily criticized. According to Birdsong (2006), it is vital to distinguish between the two concepts because they are intertwined. He argued that dominance could determine proficiency, but proficiency is not the only factor that determines dominance. An individual can be dominant in one language without being proficient in that language. Therefore, proficiency can be viewed as a component of dominance. It can also be averred that dominance as a construct originates from the nature of bilingualism, which involves the relationship between the level of competencies in two languages. Thus, proficiency does not require bilingual construct for its definition because monolingual proficiency is often assessed (Gertken et al., 2014). Dominance can be better conceptualized as processing abilities between two languages of $\mathrm{bi} /$ multilingual. Numerous scholars proposed a psycholinguistics' view as an alternative to the general singly notion of proficiency (Dewaele, Schmid, and Köpke 2004; Harris, Gleason, and Aycicegi 2006). Harris et al. (2006, p. 267) stated that dominance is the language that is commonly used for day to day life activities. This observation is supported by Heredia (1997), who described it based on frequent usage. Similarly, the concepts of automaticity developed by Dewaele et al. (2004) described the slow shift from L1 to L2 dominance. Other attitudinal factors, such as cultural identification and motivation, which have an indirect effect on language dominance, have been identified (Marian et al., 2007; Pavlenko, 2004). In sum, the concept of language dominance is highly influenced by several socio-psycholinguistic factors.

The concept of domain analysis introduced by Fishman 1986 detailed the use of language in various social institutions such as home, workplace, and market place in a multilingual setting. The determination of language choice bifurcates into socio-psychological levels of intimate, informal, formal and intergroup and societal institutional level, existing either in home, school, and workplace. According to Bayer (1990, p. 101), these determinants served as a deciding factor for the development of language function because of the specific roles they play in different settings. For instance, Mother tongue is generally adopted at home and in-group interaction while the dominant language of the public is used in schools, workplace, and marketplace. This is evident in a multilingual country like India, where the majority are competent in using English, Hindi, and their respective State languages, which is the Mother tongue. According to Kachru (1986a, pp. 8.36-37), English is used in public and personal domain and serves as a linguistics tool to unite the country administratively. Several studies have attempted to investigate the use and function of language in different domains in India. In the investigation of the pattern of language use among family, friends, and institution (Sahgal, 1991), the survey demonstrated that L1 is commonly spoken at home while English is the dominant language among friends and in the institution domain.

Further research to determine language maintenance and shifting between formal and informal settings among Bengalis and Punjabis living in the Hindi-speaking city of Delhi showed high usage of maintenance of Bengali in an informal setting. At the same time, English and Hindi are used in the formal domain (Mukherjee, 1996; Ramanathan, 1999). All these observations reveal that English is the dominant language used in India.

It is also essential to account for the percentage of balanced bilinguals in a community. According to Grosjean (1998), determining the number of balanced bilinguals with an equal level of proficiency in both languages is rare. This is because such bilinguals use their language in different domains, and there is a tendency to be more dominant in one domain than the other due to variation in frequency usage. Regarding the measurement of dominance, there is little agreement on the standard method to assess the degree of dominance. Some made use of speech data to measure children's language 
abilities (Yip \& Matthews, 2006). The scholars used the mean language utterance (MLU) technique to evaluate and compare language dominance within and between CantoneseEnglish bilingual children. The subject group that recorded the highest $M L U$ in one of the languages is considered to be dominant in that particular language. Another approach adopted to operationalize proficiency to determine dominance is by asking children to give oral picture description in both languages in order to ascertain the level of fluency in the respective languages (Daller et al., 2011). Also, a self-report of language experienced-based variables. For example, the amount of exposure to a language has also been used as a proxy to determine relative proficiency. It is based on the earlier study that revealed that the level of exposure to a language is directly proportional to the level of proficiency (Döpke, 1992). Other several selfreport questionnaires probing different aspects of language experience and proficiency are bilingual dominance scale and self-report classification scale (Dunn \& Tree, 2009; Marian et al., 2007). Some of the advantages that selfreport has over performance-based approaches such as MLU as an instrument to measure dominance is that they are easier to use in eliciting more information, that determines nonlinguistic factors (Gertken et al., 2014).

This present study will be using the Friend List tool on Facebook to determine dominance in interpersonal relationship domains such as families, friends, and acquaintances. This study favoured interpersonal relationship communication approach over social institutions such as home, the marketplace, workplace amongst others because previous studies demonstrated that these social institutions do not influence multilinguals choice of language (Gal, 1979; Pascasio \& Hidalgo, 1979). In support of this assertion, it can be argued that two family members who work in the same office and communicate in L1 at home will not switch to L2 at the workplace because it is the official language of the workplace. However, it is probable to communicate in L2 with other colleagues provided they are compelled to do so. Additionally, the levels of familiarity with contacts in different spheres of relationship usually influence the formal and informal interaction, which consequently determines the choice of language. Having understood that in Indian situations, English tends to be used in formal situations because of its official status, it can be argued that the usage of English varies from one domain to another. Thus, language use in different domains is more influenced by the level of interpersonal relationships. During childhood in a multilingual setting, minors tend to develop different levels of social interactions that culminate in different stages of a relationship. The first stage of interaction is with family at the early age of Life, followed by friends and acquaintances at a later age. This changing of phases is usually accompanied by changes in linguistics environment, which leads to linguistic change. This can be illustrated by the case of a bilingual child who uses Mother tongue at home and might be dominant in it. However, the extent of dominance will automatically shift from L1 to L2 by the time he or she starts receiving a formal education in schools where English (in the case of India) is used as a medium of instruction and starts interacting with friends. In other words, a bi/multilingual is often dominant in one of the languages which exist according to a different level of interpersonal relationships (Olsson \& Sullivan, 2005). This current study intends to measure the level of dominance across different interpersonal relationship domains of family, friendship, and acquaintances by using the domain size and $\mathrm{bi} /$ multilingual choice of language use in each domain as a proxy to determine the dominance level of the domain. As shown in Figure 1, the notion is based on the fact that frequent usage of a language in a domain is a function of the number of people the language is communicated with (domain size), which consequently makes the language to be dominant in that domain. 


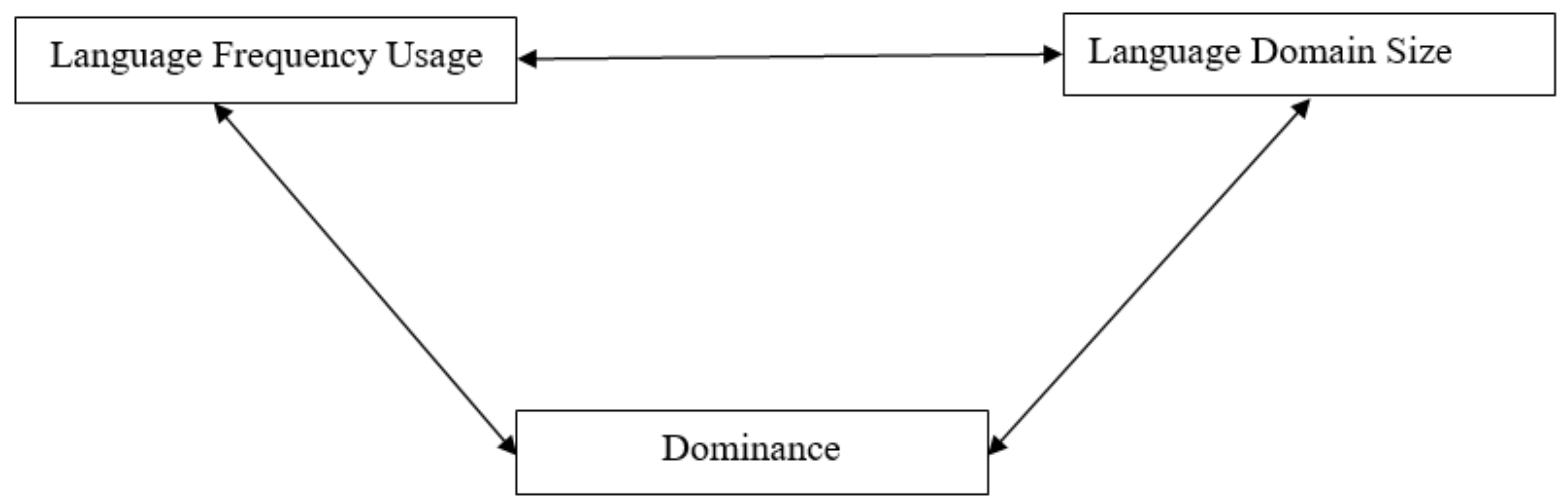

Figure 1: Schematic Representation of Language Frequency Usage as a Function of its Domain Size which determines the Dominant Language of the Domain Source: Author

There is no direct scientific instrument to elicit information on the accurate number of family members, friends, and acquaintances that we maintain constant communication with throughout our lifetime. Dunbar's number theory predicts that an individual can only maintain a steady relationship with 100 to 250 different people in his or her lifetime (Dunbar, 1992). Research such as Gonçalves et al. (2011) has validated this theory by investigating interpersonal communication on social media. Therefore, in order to be able to account for the number of people that we have steady contact with within each interpersonal relationship domain, this study will adopt the Friend List features on Facebook. Facebook is a social networking site used by $71 \%$ population of the world ("Social Media Site Usage 2014 | Pew Research Center," n.d.). There are several ways of using Facebook to communicate with individuals in the network of contacts. These methods include wall posts, personal messages, status updates, and Facebook chat.

A private message on Facebook is a confidential message which is usually sent to an individual message box. The wall post is the information shared on an individual's walls and can be viewed by everyone in the users' network of contact. Although Facebook refers to every individual in the user network of contact as a "Friend", it possesses a tool that allows users to organise and classify contacts on their network into different groups. A user is given the option of listing an individual as a family, friend, or acquaintance. In order to add an individual as a family, a user needs to make use of the Smart lists feature, which contains other lists such as Work, School, and City. The feature notifies users to add the individual as any of the listings. A family member can add an individual to the family listing. Users tend to add their best friends into the close friend list, which gives them the privilege to see more of them in their News Feed and get notified each time they post.

Meanwhile, users can add an individual who they often message, wall post, like, or comment on Facebook to acquaintance list. This list is likely to consist of old classmates, business contacts, and distant colleagues, amongst others. Considering these three levels of interpersonal relationships on Facebook, it is convenient to argue that every user is inclined to have more acquaintances than close friends, and then least family members (Lasekan, 2018).

It is important to point out at this juncture that the instrument capable of assessing dominance across different levels of social-relational domains among people of the same or different multilingual speech community is yet to be invented. It is imperative to state that the creating of a tool that can measure oral and written dominance in different domains will help to determine language status, which consequently informs decisions in various sectors of the society such as education and commerce. Furthermore, hitherto, there is no methodological approach to assess the domain, which accommodates the equal usage of two 
languages despite the established existence of balanced bilingualism even though its occurrence is considered to be a rare phenomenon.

Taking these backdrops into account, this study aimed to determine the level of oral and written dominance in different levels of interpersonal relationship domains of family, friend, and acquaintance using the domain size as a proxy for dominance among individuals of the several multilingual communities in India. The questions underlying this research were:

- What is the language dominance for oral and written communication among families, friends, and acquaintances?

- Which domain do balanced bilinguals exist for the oral and written communication?

- What is the size of each language domain?

\section{Methodology}

As stated above, this study aimed to examine the dominance of oral and written language in different spheres of interpersonal relationships. Facebook friend list was used as an instrument to determine language choice and size in each domain. This experimental approach adopted a positivist position by collecting primary data from postgraduate students whose ages range between 23 and 27 . It then compared the observed results and came to conclusions regarding the choice of language use for Facebook texting and face to face communication. The data were collected at a Central University in South India. Prior to undertaking the investigation, ethical clearance was obtained from the research unit of the university. All the ethical guidelines in the protocol, such as obtaining written informed consent from the participants, were upheld. The site was selected for data collection because it comprises students from different multilingual entities from various parts of India. All the students are proficient in at least three languages, which include Hindi, English, and their respective State language. The majority of the participants are from South India who speaks Telugu, Kannada, Tamil, and Malayalam. This availed the opportunity to conduct a pan South India multilingual studies.

One of the significant factors that influence any Indian multilingual speaker language behaviour during face to face and online communication is the level of confidence to speak and write in all the national languages. Therefore, to ascertain that all the participants are proficient in the country's national languages, participants were asked to express their level of confidence in Hindi and English. A questionnaire was administered among 55 respondents, but 43 were considered for this study because of their confidence to write and speak in Hindi, English, and their respective mother tongues. The design of the questionnaire was based on previous work eliciting choice of language among multilinguals (Lasekan, 2018). This anonymous questionnaire was divided into two parts. The first part dealt with demographic questions that require the respondents to answer questions such as the level of proficiency in speaking and writing of Hindi, English, and their respective Mother tongue. It also involves the number of friends on their Facebook Friend List and their percentage composition concerning the family, friend, and acquaintance, usage of Facebook friend list features and a number of years they have been using social media. The second part requires the participants to nominate an individual from their circle of family, friends, and acquaintances. The nomination must fulfil several criteria. Firstly, he or she must belong to the respondents' multilingual community, and their competency in both spoken and written languages accommodated must be vouched for in that community. Secondly, the nominee must be a contact of the respondent on Facebook. This nomination process was followed by questions to examine and determine the choice of language used for offline and Facebook chatting. After that, the selected focus group was probed in order to understand the factors that influence language choice and use. All the different multilingual groups were represented in the focus group. The goal is to provide accurate qualitative data for a study whose sample size is small. Finally, the quantitative data findings 
were analysed using the relevant mathematical procedure.

\section{Results}

It has been already discussed that out of 55 graduate students that participated in this study, only 43 students' responses were considered for analysis because of their confidence to write and speak both in English and Hindi. These two languages serve as either L2 or L3 for South Indians. Figure 2 displays the percentage range of contacts that belongs to each level of interpersonal relationship. Family accounted for $1 \%$ to $5 \%$ of the family members in their Friend list. This is followed by close friends ( $3 \%$ to $27 \%$ ), then (17\% to $85 \%)$. This finding revealed that the majority of users' contacts are acquaintances.

Regarding Facebook texting, Table 1 shows that the majority of the Subjects prefer to communicate through texting on Facebook with their family members in Mother tongue. However, the same group of people preferred to use English while texting their acquaintances.

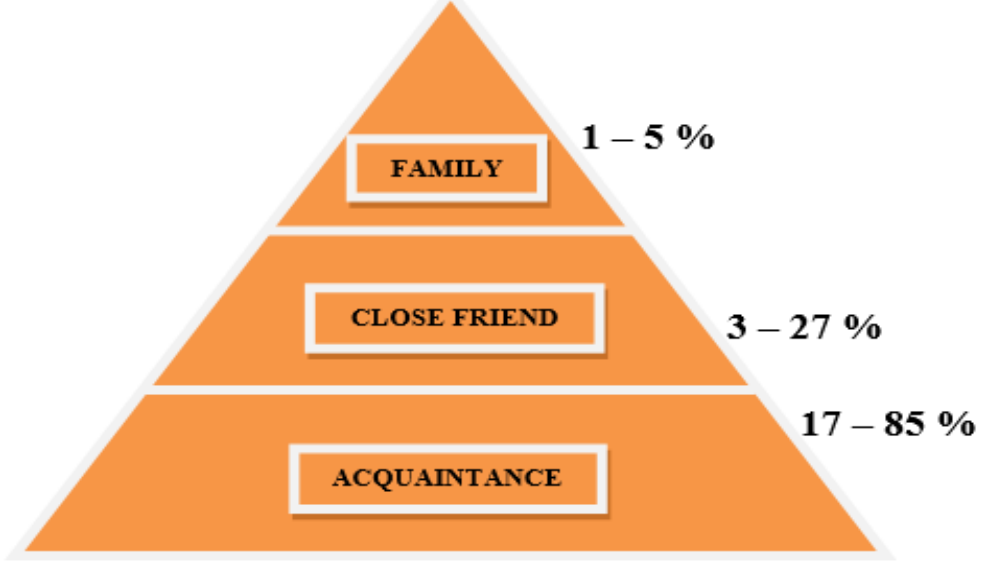

Figure 2: The Percentage Range of Family Members, Friends, and Acquaintances in Respondents' Facebook Network of Contacts Source: Author

With respect to Face to Face communication, Table 2 shows that the dominant language across the domains is the Mother tongue. For example, all the participants claimed to be speaking with their family member in their respective Mother tongues.

Figure 3 shows the overall dominant language for written communication in the entire society. Based on the domain size and percentage of interlocutors, the language dominance for written communication is English which is prevalent among acquaintances. Over $60 \%$ of the Subjects tend to message in English within that domain. Though the frequent usage of $L 1$ is mostly high among family, the percentage of users reduce across friends and acquaintances, respectively.

Figure 4 shows the dominant language used for oral communication in the whole geographical setting. The dominant language in this mode is the Mother tongue. All participants adopted their L1 for oral communication with a family member while $81 \%$ and $71 \%$ said that they communicate in the language with friends and acquaintance, respectively. 
Table 1: Language Dominance for Written Communication

\begin{tabular}{|c|c|c|c|c|c|c|c|c|c|}
\hline & \multicolumn{3}{|c|}{ Family } & \multicolumn{3}{|c|}{ Close Friend } & \multicolumn{3}{|c|}{ Acquaintance } \\
\hline Participants & English & Hindi & $\begin{array}{l}\text { Mother } \\
\text { Tongue }\end{array}$ & English & Hindi & $\begin{array}{l}\text { Mother } \\
\text { Tongue }\end{array}$ & English & Hindi & $\begin{array}{l}\text { Mother } \\
\text { tongue }\end{array}$ \\
\hline Participant 1 & $\checkmark$ & & & $\checkmark$ & & & $\checkmark$ & & \\
\hline Participant 2 & & & $\checkmark$ & & $\checkmark$ & & & $\checkmark$ & \\
\hline Participant 3 & & $\checkmark$ & & $\checkmark$ & & & $\checkmark$ & & \\
\hline Participant 4 & $\checkmark$ & & & & & $\checkmark$ & $\checkmark$ & & \\
\hline Participant 5 & & & $\checkmark$ & & & $\checkmark$ & & & $\checkmark$ \\
\hline Participant 6 & & & $\checkmark$ & $\checkmark$ & & & $\checkmark$ & & \\
\hline Participant 7 & $\checkmark$ & & & & & $\checkmark$ & $\checkmark$ & & \\
\hline Participant 8 & & & $\checkmark$ & $\checkmark$ & & & $\checkmark$ & & \\
\hline Participant 9 & $\checkmark$ & & & & & $\checkmark$ & $\checkmark$ & & \\
\hline Participant 10 & & $\sqrt{ }$ & & $\checkmark$ & & & & & $\checkmark$ \\
\hline Participant 11 & & & $\checkmark$ & $\checkmark$ & & & & $\checkmark$ & \\
\hline Participant 12 & $\checkmark$ & & & $\checkmark$ & & & $\checkmark$ & & \\
\hline Participant 13 & & & $\checkmark$ & $\checkmark$ & & & & & $\checkmark$ \\
\hline Participant 14 & & & $\checkmark$ & $\checkmark$ & & & & & $\checkmark$ \\
\hline Participant 15 & $\checkmark$ & & & & & $\checkmark$ & $\checkmark$ & & \\
\hline Participant 16 & & & $\checkmark$ & $\checkmark$ & & & $\checkmark$ & & \\
\hline Participant 17 & & & $\checkmark$ & & & $\checkmark$ & $\checkmark$ & & \\
\hline Participant 18 & $\checkmark$ & & & & & $\checkmark$ & $\checkmark$ & & \\
\hline Participant 19 & & $\checkmark$ & & $\checkmark$ & & & & & $\checkmark$ \\
\hline Participant 20 & $\checkmark$ & & & & & $\checkmark$ & $\checkmark$ & & \\
\hline Participant 21 & & & $\checkmark$ & & $\checkmark$ & & $\checkmark$ & & \\
\hline Participant 22 & $\checkmark$ & & & & & $\checkmark$ & $\checkmark$ & & \\
\hline Participant 23 & & $\sqrt{ }$ & & $\checkmark$ & & & & $\checkmark$ & \\
\hline Participant 24 & & & $\checkmark$ & & & $\checkmark$ & & $\checkmark$ & \\
\hline Participant 25 & & & $\checkmark$ & $\checkmark$ & & & & & $\checkmark$ \\
\hline Participant 26 & $\checkmark$ & & & & & $\checkmark$ & $\checkmark$ & & \\
\hline Participant 27 & & & $\checkmark$ & & & $\checkmark$ & $\checkmark$ & & \\
\hline Participant 28 & & & $\checkmark$ & & & $\checkmark$ & & & $\checkmark$ \\
\hline Participant 29 & $\checkmark$ & & & $\checkmark$ & & & $\checkmark$ & & \\
\hline Participant 30 & & & $\checkmark$ & $\checkmark$ & & & $\checkmark$ & & \\
\hline Participant 31 & $\checkmark$ & & & & & $\checkmark$ & $\checkmark$ & & \\
\hline Participant 32 & & & $\checkmark$ & & $\sqrt{ }$ & & $\checkmark$ & & \\
\hline Participant 33 & $\checkmark$ & & & & & $\checkmark$ & $\checkmark$ & & \\
\hline Participant 34 & & & $\checkmark$ & $\checkmark$ & & & & $\checkmark$ & \\
\hline Participant 35 & & & $\checkmark$ & & & $\checkmark$ & & & $\checkmark$ \\
\hline Participant 36 & $\checkmark$ & & & & $\checkmark$ & & $\checkmark$ & & \\
\hline Participant 37 & & & $\checkmark$ & $\checkmark$ & & & & & $\checkmark$ \\
\hline Participant 38 & & & $\checkmark$ & & & $\checkmark$ & & $\checkmark$ & \\
\hline Participant 39 & $\checkmark$ & & & & & $\checkmark$ & $\checkmark$ & & \\
\hline Participant 40 & & & $\checkmark$ & $\checkmark$ & & & $\checkmark$ & & \\
\hline Participant 41 & & & $\checkmark$ & & $\checkmark$ & & $\checkmark$ & & \\
\hline Participant 42 & & $\sqrt{ }$ & & & $\sqrt{ }$ & & & $\sqrt{ }$ & \\
\hline Participant 43 & $\checkmark$ & & & $\checkmark$ & & & $\checkmark$ & & \\
\hline $\begin{array}{c}\text { Sum of } \\
\text { Participants }\end{array}$ & 16 & 5 & 22 & 19 & 6 & 18 & 27 & 7 & 9 \\
\hline
\end{tabular}

\section{Source: Author}


Table 2: Language Dominance for Oral Communication

\begin{tabular}{|c|c|c|c|c|c|c|c|c|c|}
\hline & \multicolumn{3}{|c|}{ Family } & \multicolumn{3}{|c|}{ Close Friend } & \multicolumn{3}{|c|}{ Acquaintance } \\
\hline Participants & English & Hindi & $\begin{array}{l}\text { Mother } \\
\text { Tongue }\end{array}$ & English & Hindi & $\begin{array}{l}\text { Mother } \\
\text { Tongue }\end{array}$ & English & Hindi & $\begin{array}{l}\text { Mother } \\
\text { tongue }\end{array}$ \\
\hline Participant 1 & & & $\checkmark$ & & & $\checkmark$ & & & $\checkmark$ \\
\hline Participant 2 & & & $\checkmark$ & & & $\checkmark$ & & & $\checkmark$ \\
\hline Participant 3 & & & $\checkmark$ & & & $\checkmark$ & & & $\checkmark$ \\
\hline Participant 4 & & & $\checkmark$ & & & $\checkmark$ & & & $\checkmark$ \\
\hline Participant 5 & & & $\checkmark$ & & & $\checkmark$ & & & $\checkmark$ \\
\hline Participant 6 & & & $\checkmark$ & & & $\checkmark$ & & & $\checkmark$ \\
\hline Participant 7 & & & $\checkmark$ & & & $\checkmark$ & & & $\checkmark$ \\
\hline Participant 8 & & & $\checkmark$ & & & $\checkmark$ & & & $\checkmark$ \\
\hline Participant 9 & & & $\checkmark$ & & & $\checkmark$ & & & $\checkmark$ \\
\hline Participant 10 & & & $\checkmark$ & & & $\checkmark$ & & & $\checkmark$ \\
\hline Participant 11 & & & $\checkmark$ & & & $\checkmark$ & & & $\checkmark$ \\
\hline Participant 12 & & & $\checkmark$ & & & $\checkmark$ & & & $\checkmark$ \\
\hline Participant 13 & & & $\checkmark$ & $\checkmark$ & & & & $\checkmark$ & \\
\hline Participant 14 & & & $\checkmark$ & & & $\checkmark$ & & & $\checkmark$ \\
\hline Participant 15 & & & $\checkmark$ & & & $\checkmark$ & & $\checkmark$ & \\
\hline Participant 16 & & & $\checkmark$ & & & $\checkmark$ & & & $\checkmark$ \\
\hline Participant 17 & & & $\checkmark$ & & $\checkmark$ & & $\checkmark$ & & \\
\hline Participant 18 & & & $\checkmark$ & & & $\checkmark$ & & & $\checkmark$ \\
\hline Participant 19 & & & $\checkmark$ & & & $\checkmark$ & & & $\checkmark$ \\
\hline Participant 20 & & & $\checkmark$ & $\checkmark$ & & & $\checkmark$ & & \\
\hline Participant 21 & & & $\checkmark$ & & & $\checkmark$ & & & $\checkmark$ \\
\hline Participant 22 & & & $\checkmark$ & & & $\checkmark$ & & & $\checkmark$ \\
\hline Participant 23 & & & $\checkmark$ & & & $\checkmark$ & $\checkmark$ & & \\
\hline Participant 24 & & & $\checkmark$ & & & $\checkmark$ & & & $\checkmark$ \\
\hline Participant 25 & & & $\checkmark$ & & & $\checkmark$ & $\checkmark$ & & \\
\hline Participant 26 & & & $\checkmark$ & & & $\checkmark$ & & & $\checkmark$ \\
\hline Participant 27 & & & $\checkmark$ & & & $\checkmark$ & & & $\checkmark$ \\
\hline Participant 28 & & & $\checkmark$ & & $\checkmark$ & & $\checkmark$ & & \\
\hline Participant 29 & & & $\checkmark$ & & & $\checkmark$ & & & $\checkmark$ \\
\hline Participant 30 & & & $\checkmark$ & & & $\checkmark$ & & & $\checkmark$ \\
\hline Participant 31 & & & $\checkmark$ & & & $\checkmark$ & $\checkmark$ & & \\
\hline Participant 32 & & & $\checkmark$ & & & $\checkmark$ & & & $\checkmark$ \\
\hline Participant 33 & & & $\checkmark$ & & & $\checkmark$ & & & $\checkmark$ \\
\hline Participant 34 & & & $\checkmark$ & $\checkmark$ & & & $\checkmark$ & & \\
\hline Participant 35 & & & $\checkmark$ & $\checkmark$ & & & & $\checkmark$ & \\
\hline Participant 36 & & & $\checkmark$ & & & $\checkmark$ & & & $\checkmark$ \\
\hline Participant 37 & & & $\checkmark$ & & & $\checkmark$ & & & $\checkmark$ \\
\hline Participant 38 & & & $\checkmark$ & $\checkmark$ & & & $\checkmark$ & & \\
\hline Participant 39 & & & $\checkmark$ & & & $\checkmark$ & & & $\checkmark$ \\
\hline Participant 40 & & & $\checkmark$ & & & $\checkmark$ & & & \\
\hline Participant 41 & & & $\checkmark$ & & & $\sqrt{2}$ & & & $\checkmark$ \\
\hline Participant 42 & & & $\checkmark$ & $\checkmark$ & & & $\checkmark$ & & \\
\hline Participant 43 & & & $\checkmark$ & & & $\checkmark$ & & & $\checkmark$ \\
\hline $\begin{array}{c}\text { Sum of } \\
\text { Participants }\end{array}$ & 0 & 0 & 43 & 6 & 2 & 35 & 9 & 3 & 30 \\
\hline
\end{tabular}


Figure 3: Language use with Families, Friends, and Acquaintances for Written Communication on Facebook

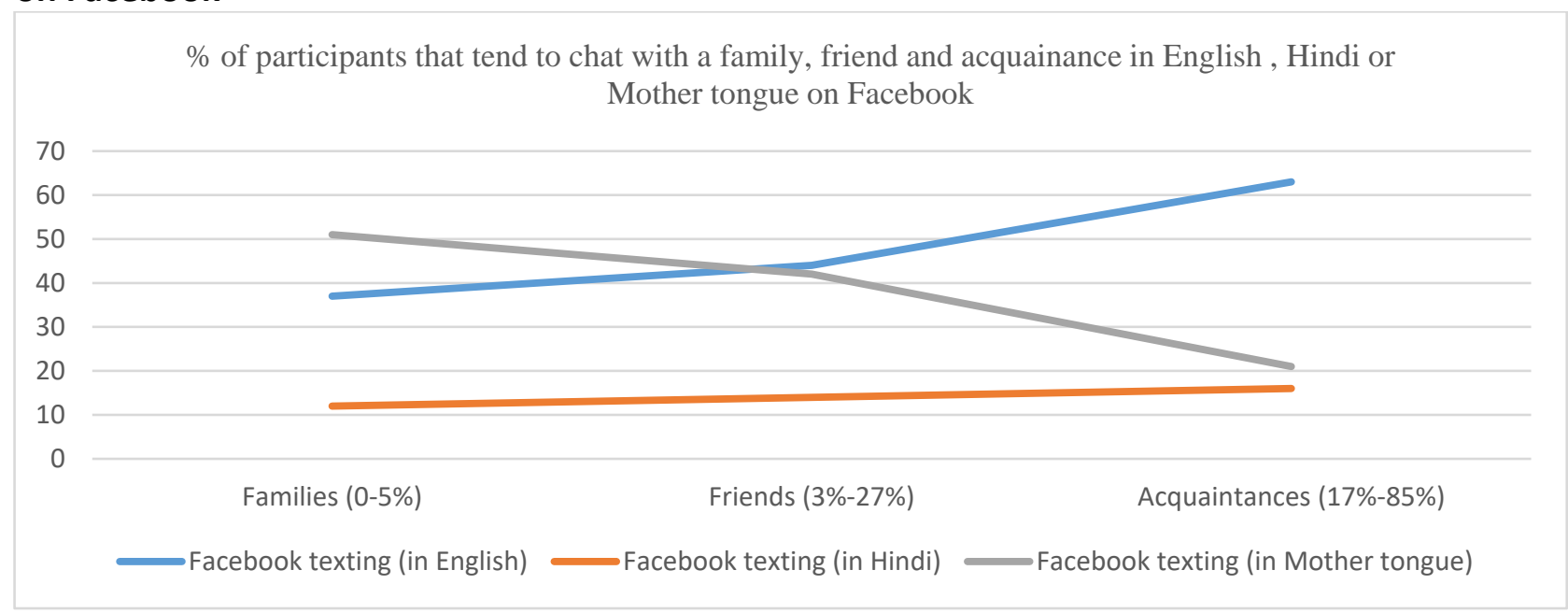

Source: Author

Figure 4: Language use with Families, Friends, and Acquaintances in the Face to Face Communication

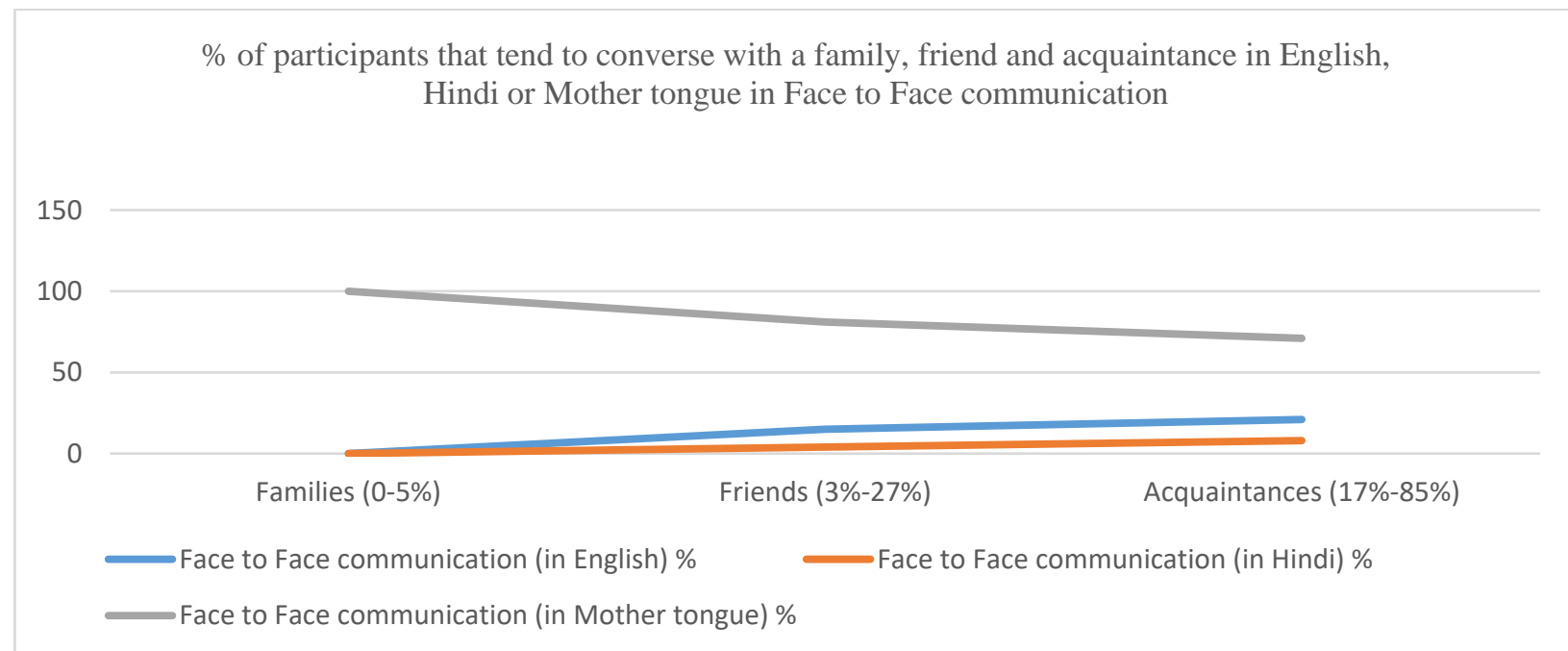

\section{Source: Author}

\section{Discussion}

The current study demonstrated that Mother tongue was the dominant language for oral communication at home where family interaction takes place (100\%), friends (81\%), and acquaintance (71\%) who can be classmates in school or colleagues in the workplace. Since L1 dominates all these domains with a high percentage of interlocutors, thus, L1 can be considered to be the overall dominant language for oral communication of the entire community. This finding is consistent with previous studies investigating language use in different social institutions domains such as home, marketplace, workplace, amongst others (Sahgal, 1991). The slight decrease of the usage of Mother tongue across family, friends, and acquaintance, respectively, can be explained with the dynamism of formal and informal language that exists at the level of interpersonal relationship. According to Ikuta (1983), conversation in most languages shift between formal and informal language, and this can be determined by the level of social and cohesion distance. Thus, an individual tends to be informal with family members and friends by adopting Mother tongue while the use of $\mathrm{L} 2$ such as English is adopted for interacting with 
acquaintances. Moreover, the disconnection of this finding with previous ones is due to drawbacks associated with past research investigating the choice of language in social institutions such as the workplace or market. It is because the question of language use in all of these domains is subjective and can be confusing to respondents. It is logical to argue that Subjects' response is based on the assumption that every language used outside the home domain should not be Mother tongue. Therefore, the propensity for every respondent to choose English as their preferred language in those domains is high. However, the choice of language for interaction depends on interpersonal relationship irrespective of the function of L2 or L3 in any of these social domains.

Regarding dominant language for written communication, English was reported to be the most prevalent among participants (63\%) that text with acquaintances. While $44 \%$ use it for friendship communication, only $37 \%$ use it for communicating with family members. On the other hand, the Mother's tongue was the most dominant language for texting among family (51\%), and its frequent usage decreased across friends (42\%) and acquaintances (21\%). Although the Mother tongue was the dominant language in the family sphere, and English was the dominant language at the acquaintance domain, the language dominance for written communication of the entire community is English. This is because English is highly used at the largest domain size of acquaintance $17 \%$ $85 \%)$, and it has the highest percentage (63\%) of interlocutors that exist within it.

It can also be observed that the majority of the participants did not make use of Hindi for oral and written communication at any level of the domains. This is because the majority of the subjects in this study are from the Southern part of India. According to Nayar (as cited in Baldridge, 1996), Hindi is a compulsory subject in schools in the Northern part of India, while most States in the South either ban the teaching of Hindi in schools or demand a low level of competence from students. All these have led to the paucity of Hindi usage in the Southern States of India, where this study is carried out.

The most significant finding in this present study was the discovery of intersection point in language use for written communication where equal usage of Mother tongue and English occur in an acquaintance domain. This point of intersection can be called the balanced bilingual zone. This present study shows that about $43 \%$ of the participants are balanced bilinguals. This is a zone that allows and accommodates people to use two languages equally. That is, two languages can function simultaneously in a domain, thereby making codeswitching to be frequent.

\section{Conclusion}

In conclusion, this study has shown that the choice of language used for oral and written interaction at different levels of interpersonal relationships can be used to determine the language dominance of an entire community. The result of the data collected from the Southern part of India showed that the Mother tongue is the dominant language for oral communication, and English is the dominant language for written communication. It also gave insight into the existence of a balanced bilingual zone that occurred within the domain of acquaintance. Most notably, this is the first study to the best of my knowledge that examined language dominance quantitatively in different spheres of interpersonal relationships. Thus, making it more applicable in different fields. One of the implications of this study is its relevance in bilingual education. Educators have been adopting the construct to determine the language in which tests of academic and linguistic ability of students should be carried out (Gertken et al., 2014). Therefore, teachers need to know the dominant language of the majority of their students and the population size of the balanced bilinguals in the class. This will help them in making an informed decision on the use of code-switching as a tool to improve the quality of instruction. Apart from its relevance in the English language teaching classroom, it can also be conducted on a longitudinal scale at different or same bi/multilingual communities, 
which can be used to determine language dominance of any society.

\section{References}

Baldridge, J. (1996). Reconciling Linguistic Diversity: The History and the Future of Language Policy in India [online]. Available at Language In India, May 2002.

Bayer, J. (1990). Language and social identity. Multilingualism in India, 61, 101.

Birdsong, D. (2006). Age and second language acquisition and processing: A selective overview. Language Learning, 56, 9-49. doi: 10.1111/j.1467-9922.2006.00353.x

Daller, M. H., Yıldız, C., de Jong, N. H., Kan, S., \& Başbaĝi, R. (2011). Language dominance in Turkish-German bilinguals: methodological aspects of measurements in structurally different languages. International Journal of Bilingualism, 15(2), 215-236. http://doi.org/10.1177/1367006910381197

Dewaele, J., Schmid, D., \& Köpke, B. (2004). Perceived language dominance and language preference for emotional speech. Studies in Bilingualism, 81. doi:10.1075/sibil.28.06dew

Döpke, S. (1992). One parent one language: An interactional approach. 3. John Benjamins Publishing. doi.org/10.1075/sibil.3

Dunbar, R. (1992). Neocortex size as a constraint on group size in primates. Journal of Human Evolution, 22(6), 469-493. doi:10.1016/0047-2484(92)90081-j

Dunn, A., \& Tree, J. F. (2009). A quick, gradient bilingual dominance scale. Bilingualism:

Language and Cognition, 12(03), 273. doi:10.1017/s1366728909990113

Fishman, J. A. (1986). Introduction to sociolinguistics, I: The sociolinguistics of society By Ralph Fasold. Language, 62(1), 188-189.

Gal, S. (1979). Language shift: Social determinants of linguistic change in bilingual Austria. Language, 56(1), 236.

doi:10.2307/412687
Gertken, L. M., Amengual, M., \& Birdsong, D. (2014). Assessing language dominance with the bilingual language profile. Measuring $L 2$ proficiency: Perspectives from SLA, 208-225. doi:10.21832/9781783092291-014 Gollan, T., Salmon, D., Montoya, R., \& Galasko, D. (2011). Degree of bilingualism predicts age of diagnosis of Alzheimer's disease in loweducation but not in highly educated Hispanics. Neuropsychologia. , 49(14), 3826-3830. doi:10.1016/j.neuropsychologia.2011.09.041

Gonçalves, B., Perra, N., \& Vespignani, A. (2011). Modeling users' activity on twitter networks: Validation of dunbar's number. PloS One, 6(8), e22656.

doi:10.1371/journal.pone.0022656

Görlach, M. (1991). Introduction to early modern English, 8-41. doi:10.1017/cbo9781139166010.004 Grosjean, F. (1998). Studying bilinguals: Methodological and conceptual issues. Bilingualism: Language and Cognition, 1(2), 131-149. doi:10.1017/s136672899800025x

Harris, C., Gleason, J., \& Aycicegi, A. (2006). When is a first language more emotional? Psychophysiological evidence from bilingual speakers. Bilingual Minds, 257-283. doi:10.21832/9781853598746-012

Heredia, R. (1997). Bilingual memory and hierarchical models: A case for language dominance. Current Directions in Psychological Science, 6(2), 34-39. doi:10.1111/14678721.ep11512617

Ikuta, S. (1983). Speech level shift and conversational strategy in Japanese discourse. Language Sciences, 5(1), 37-53. doi:10.1016/s0388-0001(83)80012-6

Kachru, B. (1986). The Alchemy of English: The Spread. Functions and Models of Oxford: Pergamon Pp. IX + 200. Canadian Modern Language Review, 43(2), 408-410. doi:10.3138/cmlr.43.2.408

Lasekan, O. (2018). Multilinguals' Choice of Language with Families, Friends and Acquaintances during Online and Offline 
Interaction. Language Art, 3(1), 85-96. doi.org/10.22046/LA.2018.05

Marian, V., Blumenfeld, H., \& Kaushanskaya, M. (2007). The Language Experience and Proficiency Questionnaire (LEAP-Q): Assessing language profiles in bilinguals and multilinguals. Journal of Speech, Language, and Hearing Research, 50(4), 940-967. doi:10.1044/10924388(2007/067)

Mukherjee, A. (1996). Language maintenance and language shift: Panjabis and Bengali in Delhi, 21, Bahri Publications.

Olsson, Å., \& Sullivan, K. P. (2005). Provoking dominance shift in a bilingual Swedish-

American English 4-year-old child. In Proceedings of the 4th International Symposium on Bilingualism. 17, pp. 50-64. Somerville, MA: Cascadilla Press.

Pascasio, E. M., \& Hidalgo, A. (1979). How rolerelationships, domains, and speech situations affect language use among bilinguals. Language and society: Anthropological issues, 111-126. doi: $10.1515 / 9783110806489.111$

Pavlenko, A. (2004). "Stop Doing That, la Komu Skazala!": Language Choice and Emotions in Parent-Child Communication. Journal of
Multilingual and Multicultural Development, 25(2-3), 179-203.

doi:10.1080/01434630408666528

Petersen, J. (1988). Word-internal codeswitching constraints in a bilingual child's grammar, Linguistics, 26(3). doi:10.1515/ling.1988.26.3.479

Ramanathan, V. (1999). "English Is Here to Stay": A Critical Look at Institutional and Educational Practices in India. TESOL Quarterly, 33(2), 211. doi:10.2307/3587718

Sahgal, A. (1991). Patterns of language use in a bilingual setting in India. English around the World, 299-307. doi:10.1017/cbo9780511611889.021

Social Media Site Usage 2014 | Pew Research Center (n.d.). Retrieved November 3, 2015, from

http://www.pewinternet.org/2015/01/09/socia I-media-update-2014/

Yip, V., \& Matthews, S. (2006). Assessing Language Dominance in Bilingual Acquisition: A Case for Mean Length Utterance Differentials. Language Assessment Quarterly, 3(2), 97-116. http://doi.org/10.1207/s15434311laq0302_2 